\title{
Impact of the World's New Technological Revolution on Economic Development and Educational Reform in the Information Age
}

\author{
Feng Cao* \\ Jiangsu Channel of zhonghongwang.com, Nanjing, Jiangsu Province, China \\ *Corresponding author: Feng Cao, 13893989@qq.com
}

\begin{abstract}
The fourth industrial revolution of human society is also known as the "world's new technological revolution," which has brought human society into the information age and has had an extremely important impact on economic development and educational reform. In the information age, economic development and wealth creation are dominated by the acquisition, mastery, distribution, and utilization of information instead of capital. Therefore, the cultivation of talents is very important, and educational reform is imperative with the rise of the world's new technological revolution.
\end{abstract}

Keywords: World's new technological revolution; Information age; Economic development; Educational reform

Publication date: November 2021; Online publication: November 30, 2021

\section{Introduction}

In the history of development of the human society, the economic development and educational progress of any age are closely related to the progress of science and technology. Especially after the human society has entered the industrial society, science and technology have been advancing at a very fast pace. In a short period of three or four hundred years, human beings had already experienced four industrial revolutions, each of which had a very huge impact on all fields of the society, including economy and education where they promoted the rapid development of these two fields. In particular, the fourth industrial revolution, known as the world's new technological revolution, is actually a completely new type of information revolution unprecedented in human history. Therefore, it has played a particularly huge role in promoting the development of economy and the progress of education ${ }^{[1]}$.

\section{Origin of the world's new technological revolution}

In western countries, there have been unfounded projections that a new technological revolution is imminent. Early in 1973, Daniel Bale, an American sociologist, put forward the concept of post-industrial society for the first time in his book, The Coming of Post-industrial Society, where he pointed out five characteristics of a post-industrial society: the economy's focus shifts from manufacturing industry to service industry; the leadership of the society changes from business owners to scientific researchers; theoretical knowledge becomes the core of society and the basis of social innovation as well as decisionmaking; future technology development is planned and moderate, and technology evaluation plays an important role; all policies need to be made through "intelligent technology" ${ }^{[2]}$. In short, in a post-industrial society, the accumulation and dissemination of theoretical knowledge become the impetus to innovation and change. 
After the publication of Bale's book, it attracted the attention of some sociologists who studied future problems, and a discussion about it was started. In 1980, Tefuler, another American sociologist, published a book, which reviewed the history and prospects of the future from the perspective of productivity development ${ }^{[3]}$. According to Tefuler, human beings have gone through two waves of civilization: the first wave brought human beings into the agricultural age from the fishing and hunting age; the second wave brought human beings into the industrial age from the agricultural age. Now, human beings are facing the impact of the third wave of civilization - from the industrial society to the information society; that is, the post-industrial society. In his book, Tefuler not only described the changes of industry and technology in the new age, such as the advent of computer, global telecommunication system, new energy, biotechnology, exploration of the space and ocean, etc., but also demonstrated the profound influence of these changes on social politics, economy, culture, and life in terms of employment, family, social organization, values, and other aspects.

After the publication of Tefuler's book, it has aroused greater repercussions in the western society. There were numerous articles about technological revolution in newspapers and periodicals, which coined each technological revolution with a different name, such as "new economy" and "information revolution," succinctly describing the changes in the new age from different angles. In 1983, the Chicago Tribune published an article by a scientific writer, Ketlecor, who also talked about this issue. Ketlecor's view is related to the so-called "Long Wave Theory" about the cyclical changes of capitalist economy put forward by the former Soviet Union economist, Kodelazief, more than 50 years ago ${ }^{[4]}$. According to Kodelazief's "Long Wave Theory," capitalist economy would develop in a cycle of about 50 years, going through four stages from recession to massive investment, to excessive construction, and eventually, chaos. Xinpeter, an Austrian economist, who believes in the "Long Wave Theory" pointed out that every economic cycle coincides with the wave of technological innovation, and the rise of emerging industries brought about by technological innovation would promote the economic recovery during recession. According to this theory, the capitalist world had its first technological revolution cycle from 1780 to 1940 (the main technological innovation was textile machinery and coal-based iron-making), its second technological revolution cycle from 1840 to 1890 (the main technological innovation was steam engine, railway, and converter steelmaking), and its third technological revolution cycle from 1890 to 1950 (the main technological innovation was electric power, chemical and internal combustion engine). In this way, the period after 1950 is of course the cycle of the fourth technological revolution; that is, the cycle of the "world's new technological revolution" as mentioned in this paper.

\section{Rise of the world's new technological revolution and its characteristics}

Stepping into the 1970s, the traditional industrial sectors in western developed capitalist countries had been shrinking and a large number of workers became unemployed, while computers, telecommunications, biotechnologies, and other sectors are developing rapidly. According to the statistics of American management expert, Delarcor, from the 1970s to the 1990s, the American manufacturing industry had lost 15 million jobs, while the American Electronics Association claimed that its subordinate companies had provided hundreds of thousands of jobs for engineers, draftsmen, computer analysts, and programmers in the past 20 years with a shortage of 240,000 mechanics for robots and electronic devices. Western Europe and Japan had a similar situation from the 1970s to the 1990s. In order to cope with this situation, the policy-making departments of western countries had gathered all kinds of forces in the past 20 years to come up with countermeasures with basic direction of reducing the production of traditional industries and encouraging the growth of new industries. Generally speaking, since the 1970s, the main technological fields that have affected the development of the world economy include electronic technology (mainly computer and telecommunication), biotechnology, new materials, and new energy. Therefore, this 
revolution can be called the "world's new technological revolution," and the "fourth industrial revolution" in human history ${ }^{[5]}$. As the fourth industrial revolution is dominated by information technology, people call this new age the information age. The "world's new technological revolution" has three important characteristics:

\subsection{Informatization}

For western industrialized countries, the world's new technological revolution has brought them into the post-industrial society; that is, the information society. The progress of microelectronics technology, improvement of the yield, and integration of large-scale integrated circuits have brought about the innovation of electronic computers. With computer memory and video disk, the reliability of storing data, sound, and image has greatly improved. With the wide application of microprocessors, the ability of information processing and calculation have also greatly improved. Communication satellites increase the reliability of space-transmitted information, ultra-high frequency band and optical fiber can realize information transmission on ground or at the bottom of the sea, and remote sensing technology has brought about a new way of data collection. The combination of information technology and communication technology leads to the establishment of complex network, which connects the world as a whole so that information can be timely processed and transmitted.

In the information society, information is a strategic resource ${ }^{[6]}$. Most people are engaged in information work, not just in commodity production. The increase of value mainly depends on knowledge, systematical production of knowledge, and constant expansion of people's intelligence. Information has become a key factor to determine productivity, competitiveness, and economic growth.

\subsection{Decentralization}

Centralization is an important feature of an industrial society because the operation of machine needs to be concentrated in labor, materials, equipment, and capital, whereas information society is a decentralized society.

Marked by the breakthrough of new technology, the development of social productive forces has made important changes in the economic structure of the society, which has also brought profound changes to people's way of life and social outlook. The information age is characterized by the application of small or microtechnology, which is epitomized by Silicon Valley. In modern society, a large company can operate quickly and efficiently with only one to two hundred employees. Owing to the gradual automation in factory and office, working from home, which does not only reduce traffic congestion, but also minimize the sue of office facilities, is becoming more common. With electronic communication by video display terminals, people's direct contact and the incidence of business trips are obviously reduced. At the same time, the increase of information resources and means of communication which extend people's leisure time would inevitably improve family life where homes would become a place for living and other intellectual activities.

\subsection{Intellectualization}

In an age marked by computers, automatic control, biotechnology, new materials, and new energy, physical strength is no longer an indicator of physical skills; instead, intelligence and knowledge have become an essential part of labor skills. The production of knowledge will become the primary "industry" and the main driving force of social and economic development. Staffs should not only have certain production experiences and labor skills, but also high level of intelligence and knowledge. For this reason, the primary task now is to increase the quantum of science and technology among the people. What needs to be emphasized here is the role of education. It is necessary to carry out various forms of training and education; 
not only advanced specialized education but also general scientific and technological education in addition to a comprehensive education. Only in this way, the new requirements of the information society for the quality of talents can be met ${ }^{[7]}$.

Among the above three characteristics, informatization is the most important and basic characteristic of the world's new technology revolution. The greatest role of the world's new technology revolution is to advance human society from the industrial age to the information age, as well as to help develop the human society from industrial civilization to information society, which would be a great progress for the human society. Information society is mainly computer-based, and from the perspective of the development of computerization, information society can be divided into four stages.

First stage: computerization based on big technology. This stage lasted from 1945 to 1970 when computers were mainly used in military and space exploration, such as calculating intercontinental missiles, Project Apollo (moon-landing project), etc. The main body of implementing computer was the state organ. Second stage: computerization of management. This stage lasted from 1955 to 1980 when the scope of computer application was mainly government agencies and business circles. The main goal of using computers was to improve the efficiency of administration and increase gross national products, such as production command, warehouse management, airline booking, etc.

Third stage: computerization of society. This stage lasted from 1970 to about 1990 when computers were mainly used to improve social welfare and meet social requirements. The general public can use computers to participate in solving certain social problems for all disciplines of sciences (including social sciences), education and medical care, pollution resolution, traffic command, resource investigation and distribution, etc.

Fourth stage: personal computerization. This stage lasts from 1990 to 2010 and later where each family has computers and mobile phones (mobile phones can be regarded as "microcomputers" or "palm computers"), and everyone can obtain the information they need from computer systems and mobile phones, solve problems, and pursue future goals. Individuals would be the main body of using computers or microcomputers (mobile phones), and science would also advance by leaps and bounds.

\section{Impact of the world's new technological revolution on economic development and educational reform}

As mentioned earlier, the world's new technological revolution has brought human society from the industrial society to the information society. Although information society is no longer a new concept today, people do not have a thorough understanding of the formation and development of the information society. In fact, this concept can be traced back to the mid-1950s when the industrial power of western developed countries was the strongest. In 1956, for the first time in western history, the number of white-collar workers engaged in technical work, management, and business exceeded those of manual workers, indicating that the western industrial society at that time had to give way to a new society. In that brand-new society, most people did not focus on producing products as before but on processing information, which was a very significant change in human history. Then, since 1957, the information revolution around the world began to sprout when the former Soviet Union launched the first man-made earth satellite in human history, whose emergence was an important catalyst in the growth of the information society because its importance did not lie in the fact that this satellite opened up the age of human space, but the fact that it opened up a new age of human satellite communication.

In 1981, the U.S. space shuttle, Columbia, was successfully launched into space and returned to the ground smoothly. The significance of this event was the same as that of the successful launch of the first man-made earth satellite by the former Soviet Union in the $1950 \mathrm{~s}^{[8]}$. This was far beyond the significance of human exploration of space technology because the space shuttle was not only to explore the space but 
also to have an important impact on the global information economy.

It can be seen from the above situation that the emergence of information society did not come after the emergence of contemporary information technology. In fact, information society was actually in the brewing stage as early as the 1950s, and the information technology at that time only played a role in ushering human beings into the information society from the industrial society at a faster pace.

1956 and 1957 can be regarded as an important turning period for the human society because this period marks the end of the human industrial age. Danilberl, a sociologist at Harvard University, calls the society after the industrial age as "post-industrial society," and in turn, the so-called "post-industrial society" is known as the "information society". The post-industrial society, that was put forward by Danilberl, had been misinterpreted for quite a long time. For example, some foreign scholars once thought that the economic focus of the post-industrial society was the expansion of the service industry. However, after a careful study of the so-called service industry, it is not difficult to see that the vast majority of workers in the service industry of today's world are actually engaged in the creation, processing, or distribution of information rather than some transactional work. Since 1956, only $11 \%$ to $12 \%$ of the world's service sector personnel are specialized in transactional work, while $88 \%$ to $89 \%$ are engaged in information or knowledge work.

Therefore, since 1956, what really grows in the post-industrial society is the information industry but not the service industry. According to relevant statistics, in 1955, only $17 \%$ of the people in the world were engaged in information work, but after the $1980 \mathrm{~s}$, the proportion suddenly increased to more than $60 \%$. At present, personnel that are engaged in information work mainly include administrative personnel, lawyers, bank staffs, technical personnel, teaching personnel, secretaries, accountants, managers, securities brokers, computer programming personnel, etc. In addition, there are a large number of people that are engaged in information work at manufacturing companies. Taking United States as an example, at present, most of the staffs are engaged in the creation, processing, and distribution of information, while Americans who are really engaged in manufacturing only account for about $13 \%$ of the staffs in the industry.

As for this situation, the history of career development in the United States is more revealing. According to statistics, from the end of the $19^{\text {th }}$ century to the beginning of the $20^{\text {th }}$ century, American farmers accounted for about $33 \%$ of the total labor force in the United States but now, they only account for about 3\%. In the early 1980s, staffs had the largest number among all jobs in the United States, workers had the second largest number, and farmers had the third largest number. The proportion of this labor force is very consistent with the characteristics of the information society because in the information society, knowledge and information are the most important factors in the whole society. From the perspective of most countries in the world today, all those who are engaged in major social work are information workers, which mainly include lawyers, journalists, social workers, accountants, teachers, engineers, priests, doctors, nurses, architects, system analysts, and computer programmers, whose major tasks in the contemporary society are to create, process, and distribute information.

In the industrial society, capital is the most important resource. The wealth of a factory depends on the amount of capital it owns. However, after entering the information society, the situation becomes different. In the information society, information is the most important strategic resource. Of course, information is not the only resource, but it is actually the most important one. Only when information becomes the most important strategic resource, then, human society can be transformed in an information society, or the economic society as usually said. The world-famous Intel Corporation of the United States can be taken as the most prominent example. As early as 1968, Intel started with USD 5 million, which was not a small sum of money in the United States, but it was also not a particularly large sum. Intel's prosperity is not largely based on its financial resources but on intelligence; that is, information resources. By 1980, Intel's sales had soared to more than USD 900 million. Bill Gates, the boss of the company, is one of the inventors 
of integrated circuits, and the company is also famous for its invention of microcomputer processors.

Information resources have been fully utilized in the United States, and there are large numbers of new enterprises in the United States every year ${ }^{[9]}$. The main reason for this prosperity is the highly developed information technology. For example, in the early 1950s, there were more than 90,000 new enterprises in the United States every year, while in the 1990s, there were more than 600,000 new enterprises every year. Nowadays, some people call the knowledge explosion phenomenon of the information age as "knowledge economy" because in the information society, human knowledge and information are widely used in various sectors and fields of social production, which is the development trend of human mental labor gradually replacing manual labor, and human knowledge and information have become a major driving force in the economic society. In such a society, people do not acquire wealth through money and power, but they create wealth through the information they have. Several people abroad once thought that knowledge productivity has become the most critical factor in today's society where knowledge and information can greatly promote the development of productivity and improve people's competitiveness in the economic society. Therefore, knowledge and information have become the most important industry in the information society, and this industry which is composed of knowledge and information provides abundant resources to economic production directly. In the information society, the growth of value is realized by knowledge and information. It is a new type of labor to engage in knowledge and information labor. An obvious example is seen under the current situation that the world market is generally shrinking where many companies in the United States can sell their management technology, industrial technology, and relevant information knowledge to many other countries in the world. The information industry in the United States was quite developed in the mid-1970s where approximately 17 million out of the 19 million new jobs created belonged to information industry departments rather than commodity production departments. This achievement fully showed that the industrial industry in the United States at that time had transformed into the information industry.

The historical significance of the transformation of the human society from the industrial society to the information society is far greater than that of the agricultural society to the industrial society with significant difference between the two. The transformation of the human society from the agricultural society to the industrial society took a long time which was about 100 years. However, the transformation from the industrial society to the information society took only 20 years which was really amazing. As the pace of human entering the information society is too rapid, people's concept of time and efficiency in the future would greatly change. Therefore, the slogan, "time is money, efficiency is life" is popular in the human society ${ }^{[10]}$.

During the period of the agricultural society, people were used to sticking to the rules along with the concept of time. For example, farmers often engaged in agricultural labor according to past experiences, such as farming in spring, plowing in summer, harvesting in autumn, and storing in winter. When entering the industrial society, the situation changed greatly. In terms of time characteristics, the industrial society do not pay as much attention to past experiences as the agricultural society does instead, they emphasized more on the present; that is, paying attention to the full use of present time. In the information society, people's concept of time had undergone fundamental changes where people pay more attention to the future. For example, people would make scientific predictions of the future according to the current situation. If they do not bother to understand the future trend, it would be difficult for them to weather through the fierce competition.

Of course, social development is not very balanced. Although developed countries or some moderately developed countries in the world have entered the information society, some countries are still in the industrial society while some other countries are still in the stage of the agricultural society. Even within a country, especially a big country, there may be unbalanced development in different regions. For example, 
at the present stage, some parts of a big country may be in the agricultural society; some may be in the industrial society; some developed regions have transformed into the information society. It is necessary to point out that in the agricultural society, the main subject of competition of the human society is nature, and not the human society itself whereas in the industrial society, the subject of human competition to some extent changed into "man-made nature," and in the information society, and the subject of human competition is completely different from that in the past; that is, a new competition in the mutual cooperation between people where the competition is more intense than ever.

In the period of transition from industrial society to information society, there are usually five important changes. (1) "Information" is not an abstract concept in social life, but it involves a lot of economic elements. In other words, "information" is the most important driving force to promote economic development, and it does have an important influence on people's various economic activities all the time. (2) The highly developed computer technology and communication technology have greatly shortened the time of human information exchange and accelerated the process of information industrialization. (3) In the information intensive society, human beings often read, write, and calculate using computers (including "microcomputers" or "palm computers"), which have become the most important communication tools in the information age. (4) In the process of changing from one social stage to another, there is always a transition stage. The new and developed information technology plays a transitional role in economic production. That is to say, latest information technologies are first used to solve old production tasks and carry out necessary transformations in the production structure of the industrial society. Only after a considerable period of time, new information technologies can be used in new production activities in the information society to produce new production methods and new information products. (5) Every information technology in the information age is not absolutely successful, but the key lies in how people apply these new information technologies. The success of technology application mainly depends on whether the technology can meet the needs of social production.

In the information society, communication technology is very important ${ }^{[11]}$. Communication technology in the information society is generally composed of three parts which include the sender of information, the receiver of information, and the communication circuit or communication cable. The increasingly developed information technology of the human society has brought about revolutionary changes in communication technology. The important result of this change is shown in the aspect of communication technology where the speed of information exchange using communication lines has greatly accelerated. Scientists specially use a new term, "shorten the flow of information," to express this result. It is because of the accelerated speed of information exchange, the information society can create vast material wealth and spiritual wealth at a speed that people can hardly imagine, thus speeding up the pace of human development.

Speeding up the time for information exchange is of great significance in the development of human society. Now human beings are able to use computers to send letters or remittances to many places on the earth at the speed of light, greatly shortening the time of information flow. In the past, people used currency for commercial trade but today, people can convert monetary capital into electronic information so as to realize various kinds of trade in an extremely short time.

In human history, data communication technology had only emerged more than 100 years ago, but now it has made greater progress due to the rapid development of computer technology. At present, computers, televisions, and mobile phones have been integrated into a very advanced communication and information system. This trinity combination does not only transfer data, but it also enables information communication and interaction between humans and computers. In addition, it can also provide an important driving force for the information society, and its role is no less important than that of nuclear energy, electricity, oil, and other energy sources in the industrial society. Once human beings enter the information society, there would 
be a very significant change where the economic operation of the information society is based on highly renewable information resources. In other words, after transitioning into the information society, there would be no shortage of information resources. For example, the western developed countries can publish a large number of scientific research articles every day, and the scientific information usually doubles every five years. Due to highly developed scientific information, the human society does not only have a lot of information resources, but it also produces more experts and scholars.

In the face of such huge information resources, there is no way to deal with it by using any technical means in the past society. For this reason, too much information is more likely to cause pollution and a waste of information resources. However, according to the current development of human information technology, advanced information technology can systematize information resources so as to avoid or reduce the waste of information resources and pollution. In addition, new information technology can also enable human beings to obtain useful information quickly and conveniently through the information system, as well as to transform useful information into resources that have a great effect on social production and social life. It is precisely because of the good development and utilization of information resources, countless electronic publications have sprung up in today's world. These electronic publications can provide people from different industries with all kinds of databases they need and enable users to choose what they want. Nowadays, the information industry all over the world has become a new industry that can produce huge economic benefits ${ }^{[12]}$.

It can be seen that in the new information society, labor skills mainly depend on knowledge and intelligence instead of physical strength. Knowledge and intelligence have become one of the most important factors determining productivity, competitiveness, and economic development. In the past 20 years, due to the vigorous development and effective utilization of emerging technology, knowledge and intelligence play much more important roles in economic production than ever before. According to relevant statistics, in a society where machinery is the main tool of labor, the ratio of physical labor to mental labor is about 9:1 whereas in a society with more developed mechanization, the proportion of mental work increased significantly where the ratio of physical labor to mental labor is about 6:4. In the initial stage of the information society, the ratio of the two is about 5:5. According to the prediction of relevant people abroad, when information technology is highly developed, the ratio of physical labor to mental labor is almost completely opposite to the mechanized society where the ratio of the two may reach 1:9. Therefore, when the age of highly developed information technology sets in, not only the degree of intellectualization of social labor would greatly increase, but the degree of the corresponding management of intellectualization would also increase. The specific performance is when the society presents a trend of high education, the application of knowledge labor in production would greatly increase. In view of these new trends, foreign experts usually call the future information society as "intelligence society" or "advanced knowledge society". To work in this advanced knowledge society, labors do not only need production experiences and labor skills, but they also need a high level of scientific and technological knowledge. The acquisition of scientific and technological knowledge is mainly through the improvement of education level. In this sense, if any country wants to be invincible in the fierce competition in the future, the country must put education at a very important strategic position with every means to increase the investment in education.

Therefore, in the information society, the most serious challenge is the training of talents. Due to the wide application of computers, great changes have taken place in education, and the main characteristics are discussed below.

(1) The open education system composed of knowledge network would replace the current education system which is out of touch with the society. This would shorten the education gap among the people between urban and rural areas, as well as industrialized and non-industrialized countries. 
(2) The new education system would replace the traditional one. In the information society, courses suitable for the cultural foundation of various social members would be provided according to their individual abilities and different learning objectives. The traditional age-based education system would be broken down to some extent where students would be able to skip grades or take less advanced courses.

(3) The self-taught system would become an important education form in the information society ${ }^{[14]}$. The current education system is one-way from teachers to students. After the popularization of computer-assisted education, students can study on their own, while teachers are in the position of consulting and solving doubts to a certain extent.

(4) In the information society, education will emphasize the creation of knowledge. Students can make use of information through computers (including "microcomputers" or "palm computers") and create new knowledge while the traditional cramming teaching method and apprenticeship training would no longer exist.

(5) The information society will eventually take up lifelong education through which people should constantly engage with continuous education. Even the elders update their knowledge in order to adapt to new environments. Therefore, "getting a certificate from school" is no longer the final step in the entire learning process.

It was in the early 1980s that the Democratic Party senators of the United States began to appeal to the international community that with the advent of the information age, it is necessary to invest in human resources. They tried their best to explain to the world that the remarkable result of the information revolution is that it will cause a fundamental change in the working structure of the society, putting forward a new challenge to the human society. The Democratic Party senators of the United States once warned people to clearly observe the new trend of the future social development, fully mobilize the huge resources of mankind, and make efficient investment in fields that can make the society prosperous and strong to a maximum extent. In order to promote the development of social economy, two aspects - reconsidering the significance of cultivating elite talents and new plans for the development of formal education as well as continuing education - should be worked out. In the early 1980s, Canada began to pay attention to the development of education in the information age. In November 1983, Canada held a seminar entitled "The Future Development Trend of Our Society" in which the central topic was how to meet the challenges of the new industrial revolution to education. Many participants in the seminar unanimously urged the Canadian government to increase its investment in education so as to ensure that the country can take the initiative in the fierce competition in the information society. The participants also called on the Canadian government to take effective measures to change the current Canadian education system in order to serve the cultivation of the next generation with innovative spirit.

Of course, the information age not only provides new opportunities for the education of all countries in the world, but it also brings new challenges. Under the pressure of the environment especially the increasingly fierce intellectual competition, all countries in the world are forced not only to increase the investment in education, but also to strengthen the reform of their own education system. The common point of educational reform for all countries in the world is that they must make use of various conditions provided by the information society to increase the degree of opening up education to the outside world and raise the international education contact and cooperation ${ }^{[15]}$. Only by continuously opening up the education system and strengthening the absorption of internal as well as external information, then the new mechanism of education can gain lasting vitality. 


\section{Disclosure statement}

The author declares that there is no conflict of interest.

\section{References}

[1] Li Z, 2017, Globalization and the Fourth Industrial Revolution are Irresistible. China WTO Tribune, (08): 59-60.

[2] Bale D, 1984, The Coming of Post-Industrial Society, The Commercial Press, 21-46.

[3] Cui H, 1998, Looking at the Future Economy from the Changes at the Turn of the Century - An Interview with American Futurist Tefuler. Outlook Weekly, (33): 2.

[4] Ye Y, 2013, Evolution of Kodelazief's Long Wave under Ultra Long Wave. Journal of Hunan Finance and Economics University, 29(01): 59-64.

[5] Meng H, 2017, World's New Technology Revolution and China's Innovation Trend and Their Impact on the Development of Shanghai. Scientific Development, (01): 105-13.

[6] Xia L, 2007, Information Technology has become a Key Strategic Resource. China Securities Journal, (A06).

[7] Zhao Y, Hu K, Liu J, 2002, Talent Quality and Information Technology Education in the Age of Knowledge Economy. China Education Info, (08): 12-3.

[8] Qi Z, 2017, 60th Anniversary of the Successful Launch of the World's First Man-Made Earth Satellite. Space International, (09): 40-1.

[9] Lyu J, 1982, The Increase of American New Enterprises. Intertrade, (04): 17.

[10] Yuan X, 2008, The Birth and Impact of "Time is Money, Efficiency is life". Practice and Theory of Sezs, (02): 15-7.

[11] Lin Z, Shi X, 2015, Application of Computer Communication Technology in Information Age. China New Telecommunications, 17(24): 30.

[12] Hong X, 2014, Research on Economic Benefits of Enterprise Core Competitiveness Based on Information Technology. Modern Economic Information, (04): 51.

[13] Chen S, 2014, Persisting in the Strategic Position of Giving Priority to the Development of Education. Xiangtan Daily, (T01).

[14] Danbadaji, 2020, Cultivating Self-Study Ability and Promoting Quality Education. Contemporary Family Education, (10): 31.

[15] Guo Y, 2020, Analysis on Effective Mode Construction Strategy of International Cooperation in Education. Yangtze River Series, (33): 61-3. 